\title{
USING A SYNTHETIC STRANGLE TO MANAGE THE STOCK MARKET RISK
}
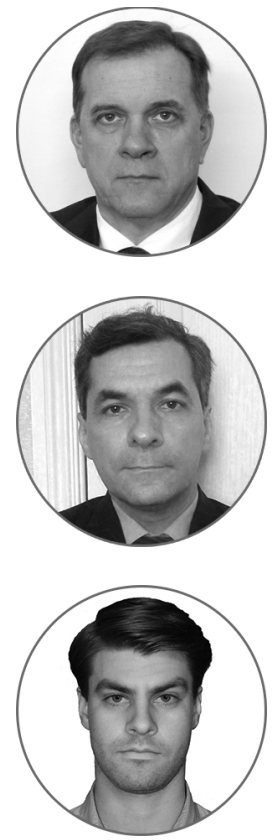

\section{Article history:}

Received 15 February 2017

Received in revised form 7 March 2017

Accepted 13 April 2017

Translated 10 July 2017

Available online 15 September 2017

JEL classification: C01, G01, G32

Keywords: synthetic option, strangle, option, equity risk

\section{Sergei N. YASHIN}

National Research Lobachevsky State University of Nizhny Novgorod, Nizhny Novgorod, Russian Federation

jashinsn@yandex.ru

\section{Corresponding author}

\section{Egor V. KOSHELEV}

National Research Lobachevsky State University of Nizhny Novgorod, Nizhny Novgorod, Russian Federation

ekoshelev@yandex.ru

\section{Vladlen V. SOKOLOV}

National Research Lobachevsky State University of Nizhny Novgorod, Nizhny Novgorod, Russian Federation

sokolov2w@gmail.com

\begin{abstract}
Importance Options are a representative example of derivative securities that are applied to mitigate investors' risks. Considering contradictions and discrepancies arising from changes in the options price due to the fluctuating price for primary securities, rather than the flat exercise price for the option, investors seek possible combinations of securities so to reduce equity risks. The article considers a synthetic options strategy - a synthetic strangle. Objectives The research models a synthetic strangle and applies it in practice using stocks of LUKOIL Oil Company. Methods The research involves methods of logic and statistical analysis.

Results We apply a symmetrical binomial lattice to determine the synthetic strangle price. Based on a binomial model, we build the model of LUKOIL's stock price movement and consider the case of synthetic strangle duplication by constructing a portfolio of stocks and bonds, which generates the same cash flows as options.

Conclusions and Relevance It is feasible to use a synthetic strangle in a situation when market stock price movements are uncertain and investors protect their capital against unexpected fluctuations in the stock market by purchasing a synthetic option. We also found break-even points for the investor.
\end{abstract}

The editor-in-charge of this article was Irina M. Komarova Authorized translation by Irina M. Komarova 
Analyzing potential investment, investors consider two principal aspects - the expected return on investment and the risk. Any investor strives to maximize the first component and reduce the second one, using various methods. In this article, we do not focus on the expected return, but rather attempt to examine one of the investment risk mitigation methods. This method involves derivative securities and the options contract, in particular. Theoretical principles and options pricing are studied in proceedings of foreign authors, such as Z. Bodie [1], L. Brandão, J. Dyer, W. Hahn [2], A.K. Dixit, R.S. Pyndyck [3], R. Merton [4], J. Cox, S. Ross, M. Rubinstein $[5,6]$, J. Hull $[7,8]$, R. Schwartz [9], L.J. MacMillan [10]; and Russian scholars, such as A.N. Burenin", A.S. Shvedov [11]. Options strategies and their use are reviewed in studies by Sh. De Kovno, Ch. Tucci ${ }^{2}$, J.F. Marshall, V.K. Bansal [12], Sh. Natenberg [13]. C. Bastian-Pinto, L. Brandão, L. Ozorio [14], G. Guthrie [15], J. Cox, S. Ross, M. Rubinstein $[5,6]$ also contributed to researches into binomial trees and their application to options. The conventional approach necessitates the exercise price of an option to be estimated. The exercise price of an option means the price that is to be paid for the underlying asset when the option is exercised. The option also depends on the time and risk [11].

Synthetic instruments stand for instruments that, if combined, create the totality of cash flows that reproduces the totality of cash flows generated from real instruments.

Following the strangle strategy, the buyer purchases a put option and a call option relating to the same underlying asset but with the different exercise price. Under this strangle strategy, the buyer pays the seller the amount equal to the value of two options (call and put). If the investors chooses to purchase this strategy, they have a yield only in case of the upward or downward swing in the price. If the investor decides to

\footnotetext{
${ }^{\dagger}$ For the source article, please refer to: Яшин С.Н., Кошелев Е.В., Соколов В.В. Применение синтетического стрэнгла для управления фондовым риском. Финансы и кредит. 2017. Т. 23. Вып. 21. С. $1214-$ 1231. URL: https://doi.org/10.24891/fc.23.21.1214

${ }^{1}$ Burenin A.N. Forvardy, f'uchersy, optsiony, ekzoticheskie i pogodnye proizvodnye [Forwards, futures, options, exotic and weather derivatives] Moscow, Vavilov Scientific and Technological Society Publ., 2005, 534 p.

${ }^{2}$ De Kovno Sh., Tucci Ch. Strategii hedzhirovaniya [Hedge Strategies]. Moscow, INFRA-M Publ., 1996, 208 p.
}

sell this strategy, a yield is generated only if the market does not fluctuate, remaining flat.

We use a binomial model to construct a synthetic strangle [16]. We resort to the binomial model, rather than the Black-Scholes model [17], since the investor combines a stock in question and risk-free bond in the synthetic strangle. In the mean time, the Black-Scholes model requires to use the risk-free interest rate only, without regarding the risk-free bond.

To clarify our further reasoning, we introduce the following denotations:

$S_{0}$ is the stock price as of the current moment of time;

$u$ is the rate of growth in the stock price estimated as to a semiannual increase;

$d$ is the rate of growth in the stock price estimated as to a semiannual decrease;

$S_{0} d$ is the projected stock price estimated as to a semiannual increase;

$S_{0} u^{2}$ is the projected stock price estimated as to a semiannual decrease;

$S_{0} u$ is the projected stock price estimated as to a yearly increase;

$S_{0} u d$ is the projected stock price estimated as to a semiannual increase and a subsequent semiannual decrease;

$S_{0} d u$ is the projected stock price estimated as to a semiannual decrease and a subsequent semiannual increase;

$S_{0} d^{2}$ is the projected stock price estimated as to a yearly decrease;

$K_{1}$ is the strike price for a call option exercised in a year;

$K_{2}$ is the strike price for a put option exercised in a year;

$C_{u u}$ is the price for a synthetic call option provided that the projected price doubles within a year; 
$C_{u d}$ is the price for a synthetic call option in case of a semiannual increase and a semiannual decrease in the projected stock price;

$P_{d u}$ is the price for a synthetic put option provided that the projected price demonstrates a two-fold drop within a year;

$P_{d d}$ is the price for a synthetic put option in case of a semiannual decrease and a semiannual increase in the projected stock price;

$O$ is the price for a synthetic strangle;

$O_{u}$ is the price for a synthetic strangle in the year end in case of a semiannual increase in the stock price;

$O_{d}$ is the price for a synthetic strangle in the year end in case of a semiannual decrease in the stock price;

$O_{u u}$ is the price for a synthetic strangle in the year end in case of a two-fold increase in the projected price within a year;

$O_{u d}$ is the price for a synthetic strangle in the year end in case of a semiannual increase and a subsequent semiannual decrease in the projected stock price;

$O_{d u}$ is the price for a synthetic strangle in the year end in case of a semiannual decrease and a subsequent semiannual increase in the projected stock price;

$O_{d d}$ is the price for a synthetic strangle in the year end in case of a two-fold decrease in the projected price within a year;

$t$ is the half year number;

$B_{0}$ is the value of a risk-free bond as of the current moment of time;

$r_{f}$ is a semiannual risk-free interest rate;

$B_{1}=B_{0}\left(1+r_{f}\right)$ is the price for a bond as at the $t=1$, i.e. in a half year;

$B_{2}=B_{0}\left(1+r_{f}\right)^{2}$ is the price for a bond as at the $t=2$, i.e. in a year;

$N_{S, 0}$ is the number of stocks needed to create an equivalent portfolio as at the $t=0$;
$N_{B, 0}$ is the number of bonds needed to create an equivalent portfolio as at the $t=0$ time;

$N_{S, 0}^{u}$ is the number of stocks needed in a half year $(t=1)$ once the $u$-situation occurs;

$N_{B, 0}^{u}$ is the number of bonds needed in a half year $(t=1)$ once the $u$-situation occurs;

$N_{S, 1}^{d}$ is the number of stocks needed in a half year $(t=1)$ once the $d$-situation occurs;

$N_{B, 1}^{d}$ is the number of bonds needed in a half year $(\mathrm{t}=1)$ once the $d$-situation occurs.

To measure the option, we use the binomial model described in the paper by C. Bastian-Pinto, L. Brandão, L. Ozorio [14].

This model requires to construct a symmetric lattice with a mathematical expectation that is a kind of the price trend. Fig. 1 and 2 indicate binomial movement.

The above figures contain the following denotations:

$x_{t}^{*} \quad$ stands for values in the combined lattice;

$x_{t}^{\prime}$ is a deterministic expected value of movement;

$\sigma$ is the mean square variance of the value;

$\mu$ is the growth rate of the value;

$p$ is the probability of the event;

$\Delta t$ is a time interval.

The Bastian-Pinto-Brandão-Ozorio model differs from the Cox one because the latter does not ingrain a drift rate into the lattice design, being a part of the probabilistic transition to each node. The researches of the authors [14] refer to cases demonstrating that this method allows for a more precise measurement of a real option.

To illustrate the model design, we use ordinary stocks of LUKOIL Oil Company, with their trends indicated in Table 1. Sometimes shareholders happen to choose whether they should retain or sell their stocks. As the price for this stock shows, the price is going down, but it is unclear whether this trend stems 
from long-standing processes or some temporary fluctuations in the market.

We assume this is a temporary reduction in the price and the investor does not intend to sell stocks, but rather plans to hedge the risk and benefit from a greater decrease or increase in prices for stocks.

To make up a synthetic strangle, the following steps should be accomplished:

1) determining the exercise price of an option (the strike price);

2) constructing a binomial model reflecting the movement of the stock price;

3) determining the price for call and put options;

4) making a synthetic strangle.

First, we determine the strike price. Whereas prices for stocks are unpredictable, prices are averaged to build forecasting models. Having found the average prices using the formula $\left(P_{1}+P_{2}+P_{3}\right) / 3$, we can show in Fig. 2 that the price-to-earnings ratio (P/E ratio) of the stock demonstrates a more approximate normal distribution, thus allowing to gauge a confidence interval of future movements of stock prices.

Referring to Table 1, we set up a confidence interval of the stock price.

The P/E ratio of a stock per year is expressed as $(1+i)^{52}-1=i_{\text {year }} \quad$, where $i_{\text {year }}=-0.162$.

$$
\begin{gathered}
\text { Annual } \quad \text { standard } \quad \text { deviation } \\
\mu_{\text {week }} \cdot \Delta t=0.0215714 \cdot 57=0.156 .
\end{gathered}
$$

equals

The confidence interval is assessed with the following formula:

$$
\bar{x}-(1.96 \cdot S E M) ; \quad \bar{x}+(1.96 \cdot S E M),
$$

where $S E M=\frac{\mu}{\sqrt{n}}$.

The example leads us to

$$
-0.162 \pm 1.96 \cdot \frac{0.156}{\sqrt{52}} ;-0.162 \pm 0.04224 \text {. }
$$

Hence, in a year, prices for stocks will range from $1,852.317$ to $2,048.964$.

The strike price for a $K_{1}$ call option shall be higher than the maximum price for a stock, i.e. being an out-of-money call. In our example, we accept the price of RUB 2,050.
The strike price for a $K_{2}$ put option is lower than the minimum value, being equal to RUB 1,850 .

After we assess the strike prices for call and put options, we measure the option value and construct a synthetic strangle. We apply the above binomial model to determine the option value.

To build a binomial model, it is necessary to assess a mathematical expectation of the P/E ratio of the stock and standard deviation. Thus, we restate figures in Table 1 into P/E logarithms and find the mathematical expectation of the $P / E$ ratio. The mathematical expectation of the $P / E$ ratio is 0.915496 . We also estimate a weekly standard deviation and compute it for a semiannual period.

Fig. 4 presents the binomial model of the stock price movement under the following conditions:

$$
\begin{aligned}
& \mu_{\text {half year }}=0.915496 ; \\
& \sigma_{\text {week }}=0.11 ; \\
& u=e^{\sigma \cdot \sqrt{\Delta} t}=e^{0.021571 \cdot 5.09902}=1.11627 ; \\
& d=\frac{1}{u}=0.89584 .
\end{aligned}
$$

To introduce a risk-free bond into our portfolio, we choose a government bond with the P/E ratio that would match a risk-free interest rate. In Russia, we may opt for the refinancing rate of 8.25 percent. The P/E ratio of bond ОФ3-29010-ПК approximates target traits, being equal to 8.677 percent $^{3}$. The current market price for this bond is RUB 105 as of November 1, 2015.

Hence, we can compute the full semiannual P/E ratio $r_{f}$ using the formula below [18]:

$$
\begin{aligned}
& \left(1+r_{f}\right)^{2}=1+r_{f \text { annual }} ; \\
& r_{f}=\sqrt{1.08677}-1=0.04248261 ; \\
& B_{1}=B_{0}\left(1+r_{f}\right)=109.461 ; \\
& B_{2}=B_{0}\left(1+r_{f}\right) 2=114.111 .
\end{aligned}
$$

Possessing all necessary data, we can make a synthetic strangle. In twelve months, the holder of this option strategy will be able to buy at the $K_{1}$ price or sell at the $K_{2}$ price the underlying stock of the contract:

$$
\begin{aligned}
& O_{u u}=\max \left\{\max \left(S_{0} u^{2}-K, 0\right), \max \left(K-S_{0} u^{2,0}\right)\right\} ; \\
& O_{u d}=\max \left\{\max \left(S_{0} u d-K, 0\right), \max \left(K-S_{0} u d, 0\right)\right\} ; \\
& O_{d u}=\max \left\{\max \left(S_{0} d u-K, 0\right), \max \left(K-S_{0} d u, 0\right)\right\} ; \\
& O_{d d}=\max \left\{\max \left(S_{0} d^{2}-K, 0\right), \max \left(K-S_{0} d^{2,0}\right)\right\}
\end{aligned}
$$

\footnotetext{
${ }^{3}$ RUSBONDS. URL: http://www.rusbonds.ru
} 
Showcasing the assessment of the option price and a choice between a call option and put option, we examine the above equation and substitute the values with ones we calculated before:

$$
\begin{aligned}
& O_{u u}=\max \{\max (2,449.969-2,050.0),\} \\
& \max \{(1,850-2,449.969 .0)\} .
\end{aligned}
$$

The first maximum $\max (2,449.969-2,050.0)$ denotes the price for a call option. This price is made up if one of two scenarios is chosen. Following the first scenario, the investor exercises the option if the price exceeds $K_{2}$. According to the second scenario, the investor does not exercise the option if the stock price does not exceed the value. In the first scenario, the price for the option equals the difference between the stock price upon the exercise of the option, and the strike price. In the second scenario, the price for the option is zero.

The second maximum $\max (1,850-2,449.969 .0)$ reflects the put option pricing. The price for a put option is formed like it is done in the example, being equal to zero.

Finally, the third maximum helps choose which option - a put or a call - is appropriate for the given situation. The highest of two prices is chosen:

$$
O_{u u}=\max \{399.969 .0\} \text {. }
$$

The maximum is 399.969. Therefore, in the $u$ u-situation, a call option should be used, with its price being 399.969.

Relying on the figures from the example, we conclude the remaining options will be as follows:

$$
\begin{aligned}
& C_{u d}=P_{u d}=0 ; \\
& C_{d u}=P_{d u}=0 ; \\
& P_{d d}=272.086 .
\end{aligned}
$$

As at $t=1$, call and put options relate to the European type, generating neither income nor expenses. It has the following meaning:

$$
O_{u}=O_{d}=O \text {. }
$$

We compose and solve three systems of equations. Each system of equations reflects nodes of the model built.

The first node is marked with a dashed line in Fig. 4. Assume we are at $t=1$ now, and stock prices equal
$S_{0} u$. At the following moment $t=2$, stock prices can have one of the two values, increasing up to $S_{0} u^{2}$ or decreasing down to $S_{0} u d$. Based on these scenarios, cash flows generated by the call-put option will amount to the volume $C_{u u}$ or the value $C_{u d}$. To create a portfolio of stocks and bonds that, as at $t=2$, would generate the same cash flows like call and put options, in particular, $C_{u u}$ and $C_{u d}$, we apply the bond price as at $t=1$, which is equal to $B_{1}$ and the reverse flow for the following period accounting for $B_{1}\left(1+r_{f}\right)$.

We present the system of equations, which will help to quantify how many stocks and bonds are needed for the equality and an equivalent portfolio:

$$
\left\{\begin{array}{l}
S_{0} u^{2} \cdot n_{S, 1}+B_{1}\left(1+r_{f}\right) \cdot n_{B, 1}=C_{u u}, \\
S_{0} u d \cdot n_{S, 1}+B_{1}\left(1+r_{f}\right) \cdot n_{B, 1}=C_{u d} .
\end{array}\right.
$$

Inserting the figures from our example, we arrive at the following system of equality:

$$
\left\{\begin{array}{l}
2,449.969 \cdot n_{S, 1}+114.111 \cdot n_{B, 1}=399.969 \\
1,966.174 \cdot n_{S, 1}+114.111 \cdot n_{B, 1}=0
\end{array}\right.
$$

The solution is as follows:

$$
\left\{\begin{array}{l}
n_{S, 1}=0.826732397, \\
n_{B, 1}=-14.24489965 .
\end{array}\right.
$$

The following system of equations results from the conditions that the stock price is $S_{0} d$ as at $t=1$. Likewise in the previous example, the stock price can grow up to $S_{0} u d$ or drop down to $S_{0} d^{2}$. Based on this condition, the equivalent portfolio is made up so to equate it to $P_{d d}$ as at $t=2$ provided the stock price is unchanged. However, if the stock price rises, it equals to $C_{d u}=C_{u d}=0$.

Thus we arrive at the following equation:

$$
\left\{\begin{array}{l}
S_{0} u d \cdot n_{S, 1}+B_{1}\left(1+r_{f}\right) \cdot n_{B, 1}=C_{u d}, \\
S_{0} d^{2} \cdot n_{S, 1}+B_{1}\left(1+r_{f}\right) \cdot n_{B, 1}=P_{d d} .
\end{array}\right.
$$

Inserting the specific figures from our example, the system of equations is as follows:

$$
\left\{\begin{array}{l}
1,966.174255 \cdot n_{S, 1}+114.111 \cdot n_{B, 1}=0, \\
1,577.914019 \cdot n_{S, 1}+114.111 \cdot n_{B, 1}=272.086
\end{array}\right.
$$


It leads us to the following solutions:

$$
\left\{\begin{array}{l}
n_{S, 1}=-0.70078298, \\
n_{B, 1}=12.07474543 .
\end{array}\right.
$$

When the mix of the equivalent portfolio is known, we select shares of securities as at $t=0$. These shares are selected so that related income, as at $t=1$, precisely match expenses at the moment:

$$
\left\{\begin{array}{l}
S_{0} u \cdot n_{S, 0}+B_{0}\left(1+r_{f}\right) \cdot n_{B, 0}=S_{0} u \cdot n_{S, 1}+B_{1} \cdot n_{B, 1}, \\
S_{0} d \cdot n_{S, 0}+B_{0}\left(1+r_{f}\right) \cdot n_{B, 0}=S_{0} d \cdot n_{S, 1}+B_{1} \cdot n_{B, 1}
\end{array}\right.
$$

Expressions in the left-hand part of the upper formula describe flows, which would proceed from holding of the stock and bond as at $t=1$, if the stock price rises (falls). The opposite part of the formulae features necessary income, which would allow financing equivalent portfolios dependent on situations as at $t=1$. Sourcing interim results and figures from the example, we arrive at:

$$
\left\{\begin{array}{l}
2,397.37 \cdot n_{S, 0}+109.461 \cdot n_{B, 0}=422.7225, \\
1,923.962 \cdot n_{S, 0}+109.461 \cdot n_{B, 0}=-26.5661 .
\end{array}\right.
$$

It gives the following solutions:

$$
\left\{\begin{array}{l}
n_{S, 0}=0.949052, \\
n_{B, 0}=-16.9239 .
\end{array}\right.
$$

If we know the values of $n_{S, 0}$ and $n_{B, 0}$, we can be certain of measures to be undertaken at $t=0$ and later on at $t=1$ so to make up an equivalent portfolio in selling and purchasing stocks and bonds, with the price of the portfolio being the same as the purchase price of the call-put option:

$$
\begin{aligned}
& n_{S, 0} \cdot S+n_{B, 0} \cdot B_{0}=0.949052 \cdot 2,345.9- \\
& -16.9239 \cdot 106=449.3722 .
\end{aligned}
$$

Obtaining all the necessary figures from the above equations, we put them into Table 2 and analyze how call and put options are duplicated. The first column indicates how many assets should be purchased or sold at a certain moment of time. Right from the onset $t=0$, 16.9239 bonds and 0.949052 stocks are sold and purchased respectively. Net expenses account for RUB 449.3722.

We assume a situation when the stock price increases in the following period. At the moment, the stock price increases up to RUB 2,397.37, thus generating RUB
2,275.225 in income, while bonds entail RUB $1,852.50242$ in expenditures. Therefore, the balance of income amounts to RUB 422.722573. However, to set an appropriate equality of balance, 0.82673 stocks shall be purchased and 14.245 bonds shall be concurrently sold. Thus, the purchase of stocks costs RUB 1,981.98353, while uncovered bonds are sold generating RUB 1,559.26096 in income. As at $t=1$, income and expenses are observed to line up. As at $t=2$, the expenses of RUB 1,625.499744 are incurred to sell the bonds, notwithstanding how the stock prices change. When the stock price grows, the stocks are sold generating RUB 2,025.46874 in revenue. As per the second scenario, the stock price drops, with the revenue being RUB 1,625.499744 only. So, in the uu-situation - stock price growth the difference between income and expenses is RUB 399.969. In the $u d$-situation, when the stock price falls down to RUB 1,966.174, income from sale of stocks will match expenses for bonds, with the balance being zero. It is noticeable that the resultant balance of 399.969 and 0 precisely match cash flows from the above options. This equality is evidence of the correctness of the synthetic strangle. Now we should earmark it for buying or selling so to derive profit in a year.

We observe what happens, if the stock price decreases down to RUB 1,923.967, as at $t=1$. Income from stocks are lower than that in the second case, but expenses for bonds remain equal RUB 1,852.5. To line up the difference between income and expenses (26.56), it is reasonable to sell stocks, derive income of RUB $1,348.28$ and purchase bonds. This transaction costs RUB 1,321.71. In the following period, if the stock price increases up to RUB 1,966.174 (the $d u$-situation), income from bonds equals expenses for stocks, with the balance being zero. This value completely matches the cash flow from the $C_{d u}$ option. In the $d d$-situation, the balance of income and expenses should be $P_{d d}$. As seen in Table 2, the values match.

If the stock price remains within the range of $K_{1}$ and $K_{2}-$ RUB 1,850 through RUB 2,050 - at the final moment of the option exercise, call and put options will keep their in-the-money position both. Such options will not be exercised since they do not generate income, with the investor suffering losses in the amount of initial investment made in the option. In our case, it amounts to RUB -499.372. However, if the market undergoes certain changes that have a positive effect on the stock price and it reaches the projected amount 
of RUB 2,449.969, the investor will be able to exercise the call and put options and earn the income amounting to RUB 2,449.969 - RUB 2,050 = $=$ RUB 399.969. Considering the initial investment of RUB 499.372, the investor has a loss of RUB 99.403. Referring to the reverse situation, when stock prices drop down to RUB 1,577.914, the investor will suffer the loss of RUB 272.086-499.372= $=-227.286$ anyway even if the investor exercises the call and put options and derives income from the difference of stock prices and the $K_{2}$ price in the amount of RUB 272.086, since the initial investment exceeds the income.

We determine what prices are break-even points for the investor. For call and put options, they amount to RUB 2,050+499.372 $=2,549.372 \quad$ and RUB $\quad 1,850-499.372=1,350.628$ respectively. The investor makes profit only when the prices go beyond these limits.

Those investors, who expect the stock prices to be unstable and go beyond the boundaries of prices as set before at the final moment of time, will opt for a long strangle strategy, i.e. buying call and put options.

\section{Table 1}

Prices for LUKOIL Oil Company's stocks, RUB

\begin{tabular}{ll}
\hline Date & Price \\
\hline January 5,2015 & 2,461 \\
\hline January 12, 2015 & 2,736 \\
\hline January 19, 2015 & 2,849 \\
\hline January 26, 2015 & $2,789.9$ \\
\hline February 2, 2015 & $3,120.1$ \\
\hline February 9, 2015 & 3,135 \\
\hline February 16, 2015 & 2,990 \\
\hline February 23,2015 & $2,981.2$ \\
\hline March 2, 2015 & 2,800 \\
\hline March 9, 2015 & 2,659 \\
\hline March 16, 2015 & 2,710 \\
\hline March 23, 2015 & 2,577 \\
\hline March 30, 2015 & $2,824.8$ \\
\hline April 6, 2015 & $2,634.9$ \\
\hline April 13, 2015 & 2,576 \\
\hline April 20, 2015 & 2,645 \\
\hline April 27, 2015 & $2,645.6$ \\
\hline May 4, 2015 & $2,691.6$ \\
\hline May 11, 2015 & 2,595 \\
\hline May 18, 2015 & 2,537 \\
\hline May 25, 2015 & $2,461.3$ \\
\hline June 1, 2015 & 2,570 \\
\hline June 8, 2015 & $2,506.9$ \\
\hline & \\
\hline
\end{tabular}

Other investors, who, by contrast, believe stock prices to be more or less stable, make profit by opening short strangle positions, i.e. selling strangles.

If the highest level of profit is RUB 449.3722 and the loss has no limits upon the sale of the strangle, the purchase of the strangle reverses the situation for the investor, when the highest loss equals the initial investment of RUB 449.3722, while the profit is unlimited.

Fig. 5 provides the payment schedule for short strangles relating to stocks with the $K_{1}$ и $K_{2}$ strike prices, maturing in year. They are depicted with a dashed line.

Hence, the proposed synthetic strangle model demonstrates the way the investor can significantly reduce the risk associated with the underlying asset. Forecasting future prices for assets, investors diverge in two directions. Some of them open long strangles trying to avoid an unnecessary risk and benefit from big swings in prices, while the others start selling the positions believing that prices will not change dramatically and generate some income, albeit limited.

Please cite this article as: Yashin S.N., Koshelev E.V., Sokolov V.V. Using a Synthetic Strangle to Manage Stock Market Risk. Digest Finance, 


\begin{tabular}{|c|c|}
\hline June 15, 2015 & $2,474.4$ \\
\hline June 22,2015 & $2,401.7$ \\
\hline June 29,2015 & $2,425.3$ \\
\hline July 7, 2015 & 2,465 \\
\hline July 13, 2015 & $2,465.4$ \\
\hline July 20, 2015 & $2,468.9$ \\
\hline July 27,2015 & $2,537.6$ \\
\hline August 3, 2015 & 2,520 \\
\hline August 10, 2015 & $2,561.1$ \\
\hline August 17, 2015 & 2,412 \\
\hline August 24, 2015 & 2,520 \\
\hline August 31, 2015 & 2,458 \\
\hline September 7, 2015 & $2,487.6$ \\
\hline September 14, 2015 & $2,403.8$ \\
\hline September 21, 2015 & 2,240 \\
\hline September 28, 2015 & 2,140 \\
\hline October 5, 2015 & $2,400.1$ \\
\hline October 12, 2015 & $2,303.8$ \\
\hline October 19, 2015 & $2,336.7$ \\
\hline October 26, 2015 & 2,320 \\
\hline November 2, 2015 & $2,511.8$ \\
\hline November 9, 2015 & 2,485 \\
\hline November 16, 2015 & 2,540 \\
\hline November 23, 2015 & $2,539.4$ \\
\hline November 30, 2015 & $2,489.9$ \\
\hline December 7, 2015 & 2,450 \\
\hline December 14, 2015 & $2,327.1$ \\
\hline December 21, 2015 & $2,310.2$ \\
\hline
\end{tabular}

Source: Moscow Stock Exchange data

Table 2

Duplication of call and put options

\begin{tabular}{|c|c|c|c|c|c|c|c|}
\hline \multirow{3}{*}{$\begin{array}{l}\text { The number of } \\
\text { assets }\end{array}$} & \multicolumn{7}{|c|}{ Payments as of the given moment } \\
\hline & \multirow{2}{*}{$t=0$} & \multicolumn{2}{|c|}{$t=1$} & \multicolumn{4}{|l|}{$t=2$} \\
\hline & & $\mathbf{u}$ & d & uu & ud & du & dd \\
\hline$n_{S, 0}=0,95$ & $-2,226.38$ & $2,275.22$ & $1,825.94$ & 0 & 0 & 0 & 0 \\
\hline$n_{B, 0}=-16,9$ & $1,777.01$ & $-1,852.5$ & $-1,852.5$ & 0 & 0 & 0 & 0 \\
\hline$n_{S, 0}^{u}=0,83$ & 0 & $-1,981.98$ & 0 & $2,025.47$ & $1,625.5$ & 0 & 0 \\
\hline$n_{B, 1}^{u}=-14,25$ & 0 & $1,559.26$ & 0 & $-1,625.5$ & $-1,625.5$ & 0 & 0 \\
\hline$n_{S, 1}^{d}=-0,7$ & 0 & 0 & $1,348.28$ & 0 & 0 & $-1,377.86$ & $-1,105.78$ \\
\hline$n_{B, 1}^{d}=12,07$ & 0 & 0 & $-1,321.71$ & 0 & 0 & $1,377.86$ & $1,377.86$ \\
\hline
\end{tabular}

Source:Authoring 


\section{Figure 1}

Steps of the symmetrical lattice construction

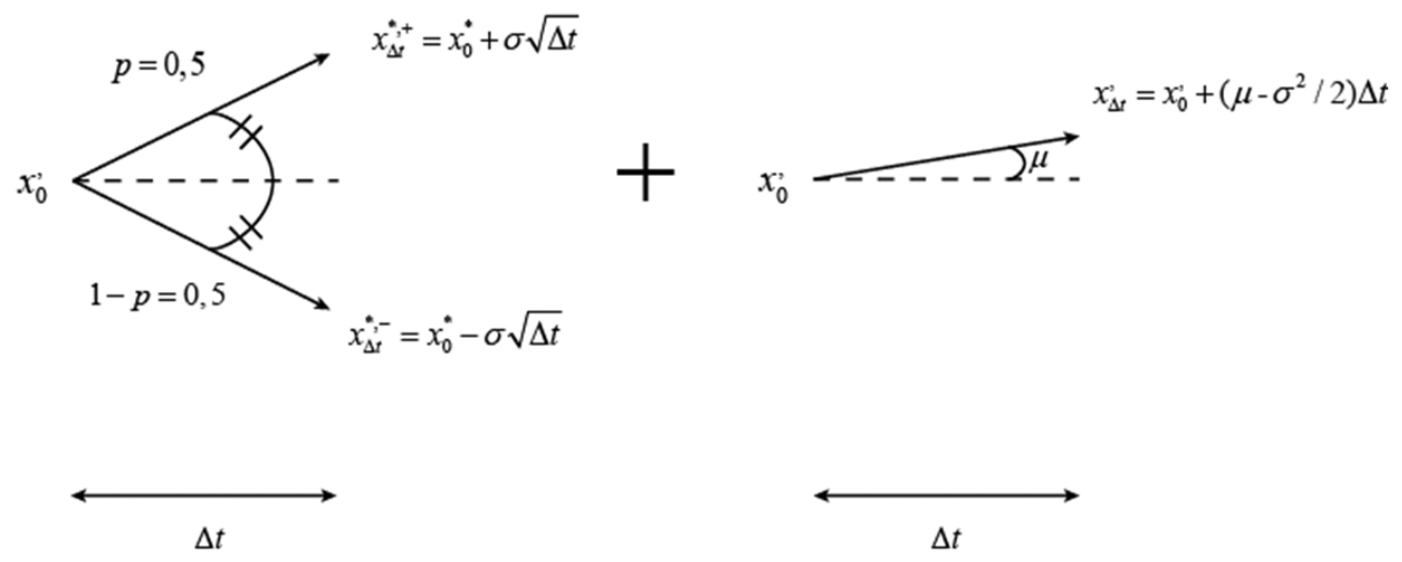

Source:[14]

Figure 2

Symmetrical lattice node

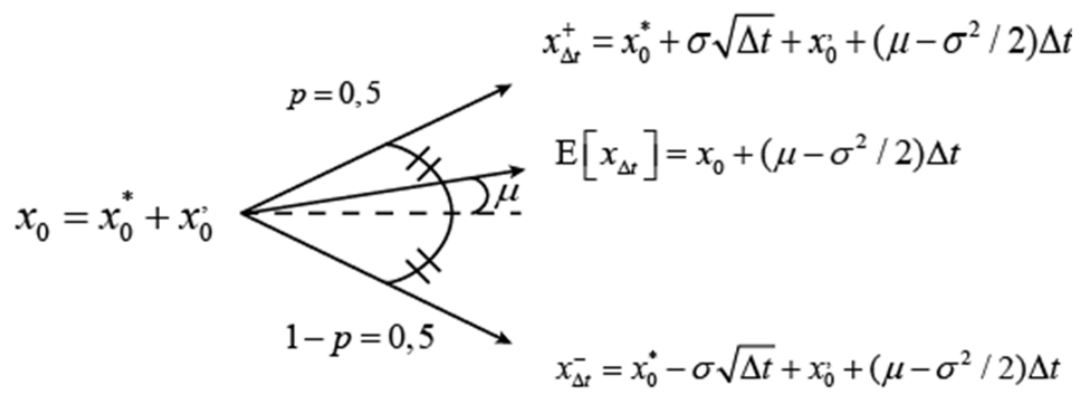

Source:[14]

Figure 3

Normal distribution of weekly $P / E$ ratio of LUKOIL's stock

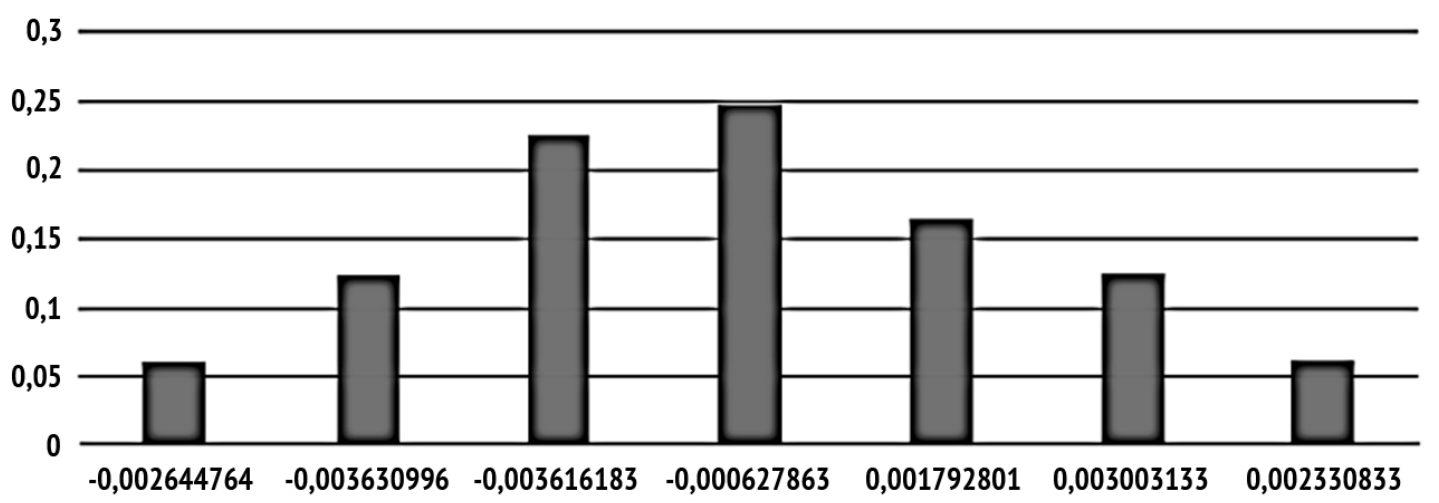

Source: Authoring

Please cite this article as: Yashin S.N., Koshelev E.V., Sokolov V.V. Using a Synthetic Strangle to Manage Stock Market Risk. Digest Finance, 
Figure 4

A price movement model of LUKOIL's stock

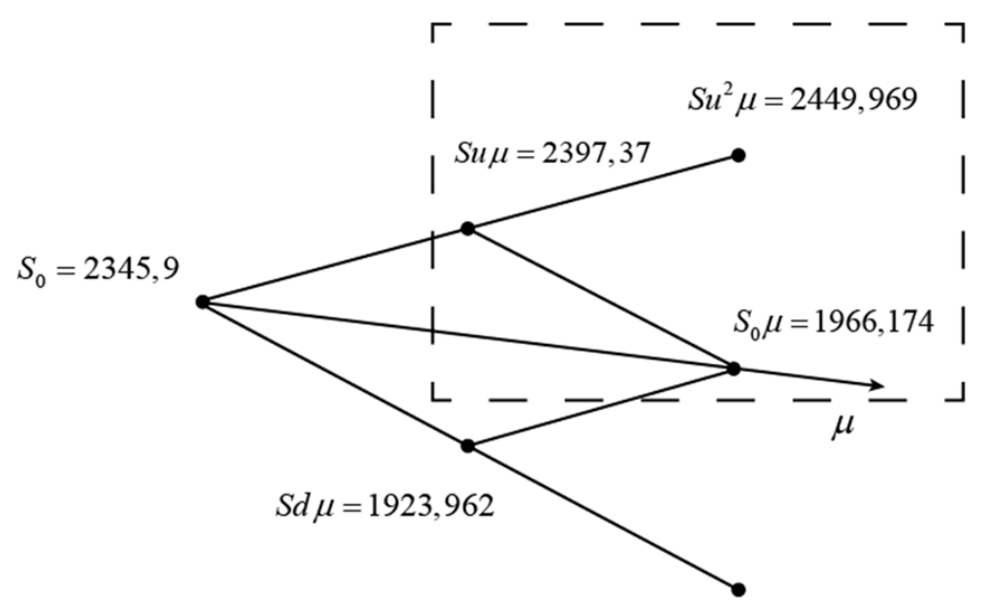

$S d^{2} \mu=1577,914$

Source: Authoring

\section{Figure 5}

Payment schedule for a synthetic strangle

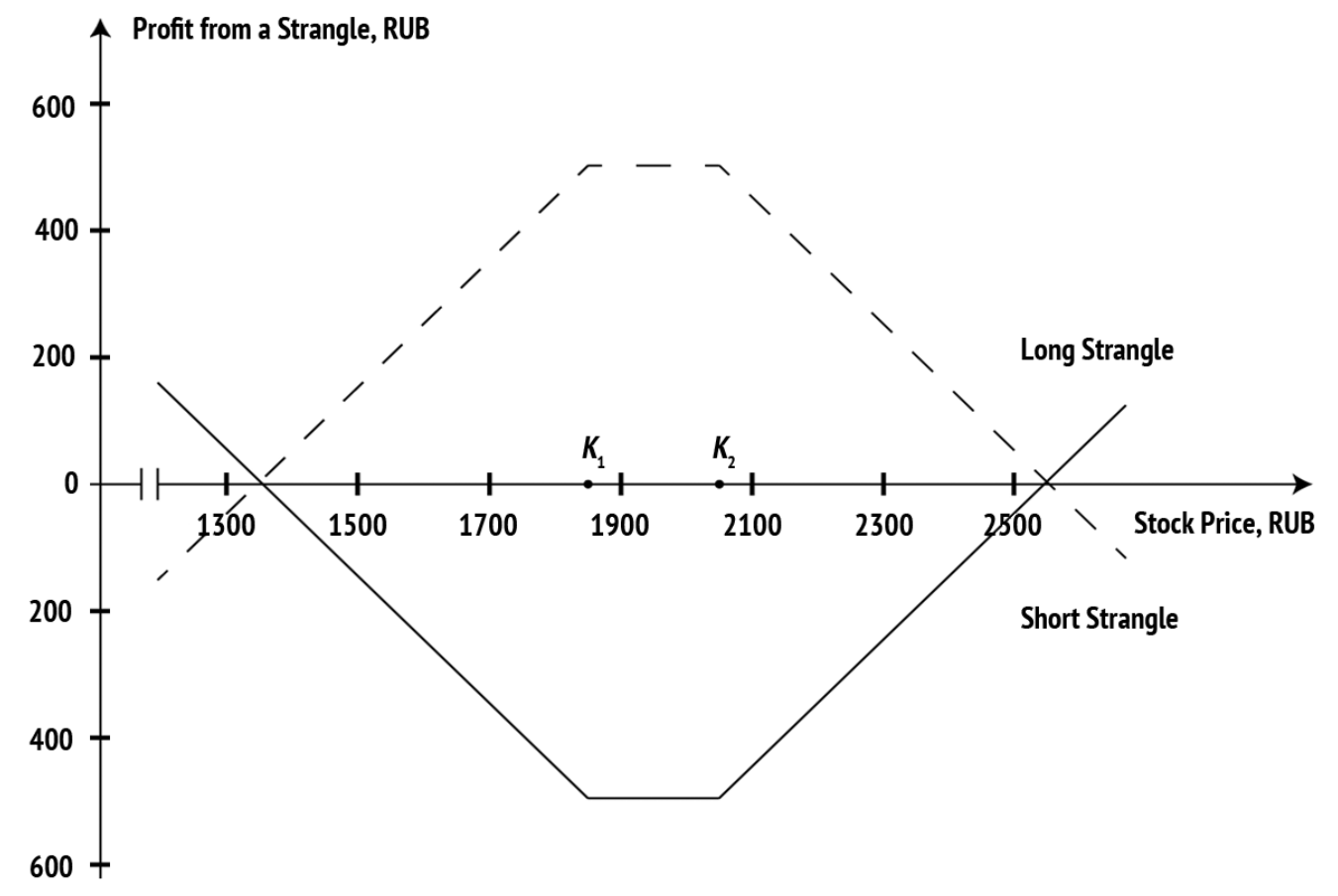

Source: Authoring

Please cite this article as: Yashin S.N., Koshelev E.V., Sokolov V.V. Using a Synthetic Strangle to Manage Stock Market Risk. Digest Finance, 2017, vol. 22, iss. 3, pp. 286-297. 


\section{Acknowledgments}

The article was supported by the Russian Foundation for Humanities, grant No. 15-02-00102.

\section{References}

1. Bodie Z. On the Risk of Stocks in the Long Run. Financial Analysts Journal, 1995, vol. 51, iss. 3, pp. 18-22. URL: https://doi.org/10.2469/faj.v51.n3.1901

2. Brandão L., Dyer J., Hahn W. Using Binomial Decision Trees to Solve Real-Option Valuation Problems. Decision Analysis, 2005, vol. 2, iss. 2, pp. 69-88. URL: https://doi.org/10.1287/deca.1050.0040

3. Dixit A.K., Pindyck R.S. Investment under Uncertainty. Princeton, Princeton University Press, 1994, 467 p.

4. Merton R. The Theory of Rational Option Pricing. Bell Journal of Economics and Management Science, 1973, vol. 4, no. 1, pp. 141-183. URL: https://doi.org/10.2307/3003143

5. Cox J., Ross S., Rubinstein M. Option Pricing: A Simplified Approach. Journal of Financial Economics, 1979, vol. 7, iss. 3, pp. 229-263. URL: https://doi.org/10.1016/0304-405X(79)90015-1

6. Cox J., Rubinstein M. Options Markets. Englewood Cliffs, N.J., Prentice-Hall, 1985, 517 p.

7. Hull J. Options, Futures and Other Derivatives. Upper Saddle River, Prentice-Hall, 2006, 869 p.

8. Biger N., Hull J. The Valuation of Currency Options. Financial Management, 1983, vol. 12, iss. 1, pp. 24-28. doi: $10.2307 / 3664834$

9. Schwartz R. Advanced Strategies in Financial Risk Management. New York, New York Institute of Finance, 1993, $688 \mathrm{p}$.

10. McMillan L.G. MakMillan ob optsionakh [McMillan on Options]. Moscow, Analitika Publ., 2002, 442 p.

11. Shvedov A.S. [Lectures. Mathematical methods used in work with options]. Ekonomicheskii zhurnal VshE = The HSE Economic Journal, 1998, vol. 2, no. 3, pp. 385-409. (In Russ.)

12. Marshall J.F., Bansal V.K. Finansovaya inzheneriya: Polnoe rukovodstvo po finansovym novovvedeniyam [Financial Engineering: A Complete Guide to Financial Innovation]. Moscow, INFRA-M Publ., 1998, 784 p.

13. Natenberg Sh. Optsiony: Volatil'nost' i otsenka stoimosti. Strategii i metody optsionnoi torgovli [Option Volatility \& Pricing: Advanced Trading Strategies and Techniques]. Moscow, Al'pina Bizness Buks Publ., 2007, 544 p.

14. Bastian-Pinto C., Brandão L., Ozorio L. A Symmetrical Binomial Lattice Approach, for Modeling Generic One Factor Markov Processes. Real Options. Theory Meets Practice: 16th Annual International Conference, Rome, Italy, June 28-30, 2012. URL: http://realoptions.org/openconf2012/data/papers/26.pdf

15. Guthrie G. Learning Options and Binomial Trees. Wilmott Journal, 2011, vol. 3, iss. 1, pp. 1-23. URL: https://doi.org/10.1002/wilj.42

16. Trifonov Yu.V., Yashin S.N., Koshelev E.V. Tekhnologii fondovogo rynka v biznese: monografiya [The stock market technologies in business: a monograph]. Nizhny Novgorod, Pechatnaya masterskaya RADONEZh Publ., 2015, $151 \mathrm{p}$.

17. Black F., Scholes M. The Pricing of Options and Corporate Liabilities. Journal of Political Economy, 1973, vol. 81, no. 3, pp. 637-654. doi: http://dx.doi.org/10.1086/260062

18. Sharpe W., Alexander G., Bailey J. Investitsii [Investments]. Moscow, INFRA-M Publ., 2001, 1028 p. 


\section{Conflict-of-interest notification}

We, the authors of this article, bindingly and explicitly declare of the partial and total lack of actual or potential conflict of interest with any other third party whatsoever, which may arise as a result of the publication of this article. This statement relates to the study, data collection and interpretation, writing and preparation of the article, and the decision to submit the manuscript for publication. 